\title{
Ultrafast photoreduction dynamics of a new class of CPD photolyases
}

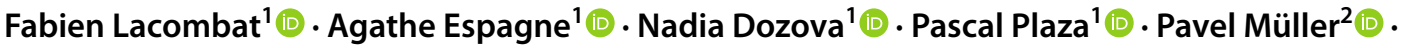 \\ Hans-Joachim Emmerich ${ }^{3}$ - Martin Saft ${ }^{3}$ (D) - Lars-Oliver Essen ${ }^{3}$ (ID
}

Received: 1 March 2021 / Accepted: 22 April 2021 / Published online: 11 May 2021

(c) The Author(s), under exclusive licence to European Photochemistry Association, European Society for Photobiology 2021

\begin{abstract}
NewPHL is a recently discovered subgroup of ancestral DNA photolyases. Its domain architecture displays pronounced differences from that of canonical photolyases, in particular at the level of the characteristic electron transfer chain, which is limited to merely two tryptophans, instead of the "classical" three or four. Using transient absorption spectroscopy, we show that the dynamics of photoreduction of the oxidized FAD cofactor in the NewPHL begins similarly as that in canonical photolyases, i.e., with a sub-ps primary reduction of the excited FAD cofactor by an adjacent tryptophan, followed by migration of the electron hole towards the second tryptophan in the tens of ps regime. However, the resulting tryptophanyl radical then undergoes an unprecedentedly fast deprotonation in less than $100 \mathrm{ps}$ in the NewPHL. In spite of the stabilization effect of this deprotonation, almost complete charge recombination follows in two phases of $\sim 950 \mathrm{ps}$ and $\sim 50 \mathrm{~ns}$. Such a rapid recombination of the radical pair implies that the first FAD photoreduction step, i.e., conversion of the fully oxidized to the semi-quinone state, should be rather difficult in vivo. We hence suggest that the flavin chromophore likely switches only between its semi-reduced and fully reduced form in NewPHL under physiological conditions.
\end{abstract}

\section{Graphic Abstract}

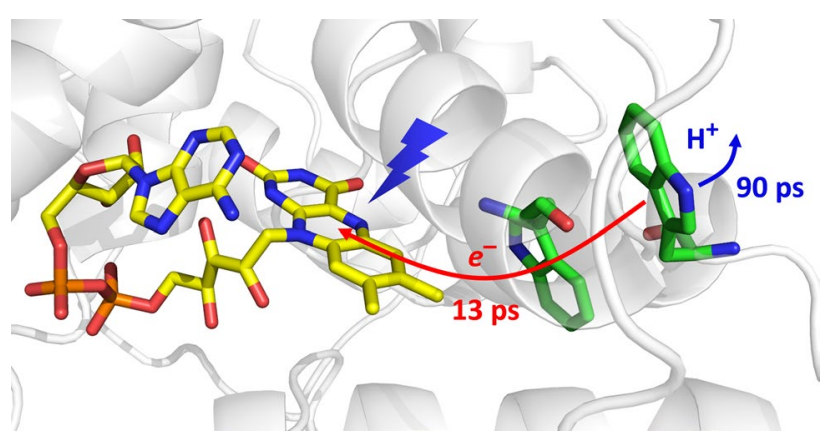

Keywords CPD photolyase · Photoactivation · Photoreduction · Electron transfer · Flavin · Tryptophan · Deprotonation · Ultrafast · Transient absorption · Spectroscopy · Anisotropy

FOREWORD: This article is dedicated to Klaus Brettel on the occasion of his retirement. Klaus has played a major role in the careers of several authors of the present article. Mentor and dear friend for some of us, close collaborator for others, he has guided us and provided us with the example of research of the highest scientific level, conducted with unfailing rigor, most discerning standards and absolute honesty.

Pushing the limits offlash photolysis to unravel the secrets of biological electron and proton transfer - a topical issue in honour of Klaus Brettel.

Extended author information available on the last page of the article

\section{Introduction}

Photolyases and cryptochromes form a superfamily (PCSf) of structurally related flavoproteins, which mediate with their non-covalently bound flavin adenine dicluneotide (FAD) numerous light-dependent functions in organisms of all kingdoms of life [1]. Photolyases are enzymes specialized in repairing UV-damaged DNA [2], i.e. pyrimidine dimer lesions, using visible light [1, 3-6]. Cryptochromes 
are blue-light photoreceptors triggering biological responses as diverse as photomorphogenesis of plants, entrainment of circadian rhythms and possibly photomagnetoreception in a number of migrating species [1,7-11].

Understanding the primary reaction mechanisms of these proteins at the molecular level has been the subject of a plethora of biological, biophysical and theoretical studies, in particular by time-resolved spectroscopic techniques, since the early works of A. Sancar and collaborators on E. coli photolyase (EcCPD) in the 1980's [12-14]. One photo-induced reaction has been particularly scrutinized, namely the process called photoactivation, by which the flavin cofactor of photolyases is photoreduced from the oxidized $\left(\mathrm{FAD}_{\mathrm{ox}}\right)$ or semi-reduced $\left(\mathrm{FADH}^{\circ}\right)$ states to the enzymatically active, fully reduced state $\left(\mathrm{FADH}^{-}\right)[1,5]$. The first photoreduction step $\left(\mathrm{FAD}_{\text {ox }}\right.$ to $\left.\mathrm{FAD}^{\bullet-} / \mathrm{FADH}^{\bullet}\right)$ is also believed to trigger the signaling process of cryptochromes [9]. Aubert et al. have demonstrated for the first time [15] that flavin photoreduction in microbial class I CPD photolyases occurs in a stepwise manner via a chain of three conserved tryptophan (Trp) residues, connecting the deeply buried flavin to the protein surface [16]. Upon photoexcitation, the flavin abstracts an electron from the first, proximal Trp (in a fraction of a ps for $\mathrm{FAD}_{\mathrm{ox}}[17]$ and in a few tens of ps for $\left.\mathrm{FADH}^{\bullet}[18,19]\right)$, producing the cationic tryptophanyl radical (noted $\operatorname{TrpH}{ }^{\bullet+}$ ). Migration of the electron hole along the Trp triad then follows in the tens to hundreds of ps [17-19]. Once the third, distal Trp is oxidized, it deprotonates in a few hundreds of ns, producing the neutral tryptophanyl radical (Trp ${ }^{\bullet}$ ). This considerably slows down charge recombination, to the ms timescale [18, 20], and leaves enough time for external reductants (thiols [14] or $\mathrm{NAD}(\mathrm{P}) \mathrm{H}[21,22])$ to quench the tryptophanyl radical, thereby stabilizing the reduced flavin. Similar patterns, involving the so-called "canonical" Trp triad, were found in the photolyases of other types of organisms [23, 24], as well as in cryptochromes [23-25]. However, a growing number of alternative electron transfer (ET) pathways have also been reported in different members of the PCSf. These include a non-canonical third Trp as final electron donor [25, 26], the hypothetical role of an aspartate (Asp) as a stepping stone between Trps [27], the involvement of tyrosine (Tyr) residues as final or alternative donors [28-32], the absence of canonical proximal Trp [31], the presence of a completely different Trp triad [33-35], branched Trp chains [36], or the existence of a fourth distal donor (Trp or Tyr) in the ET chain [32, 37-39].

In this work, we examine the unusual photoreduction chain of a new non-canonical subgroup of the PCSf, coined NewPHL, which was recently discovered by a bioinformatic approach [40]. The NewPHL subgroup is relatively small, 632 sequences with sequence lengths of 255 to 484 amino acids, and its host organisms are mostly bacteria from a marine habitat. The domain architecture of NewPHLs exhibits pronounced differences from that of other PCSf members, at both the levels of the catalytic FAD-binding domain and the C-terminal extension. Based on a homology model (Fig. 1) [40], it, moreover, appears that the canonical Trp triad is not fully evolved in NewPHL, the distal Trp being notably absent in this ancestral photolyase. This unusual configuration raises questions as to how the protein sustains the photoreduction activity reported in vitro by Emmerich et al., for both oxidized and semi-reduced forms of the enzyme, in the presence of $50 \mathrm{mM}$ dithiothreitol (DTT) as reducing agent [40]. Indeed, in the W306F mutant of $E c C P D$, where the distal Trp was replaced by a redox-inert phenylalanine (Phe), the photoreduction of $\mathrm{FADH}^{\bullet}$ was reported to be abolished in vitro in the presence of (25 mM DTT) [41]. Transient absorption studies performed on this mutant showed that charge recombination following the initial photo-induced charge separation was highly accelerated in the absence of external reductant. Starting from the semi-reduced state of the flavin, charge recombination was reported to occur in $\sim 1 \mu$ s [42], i.e. four orders of magnitude faster than in wild-type (WT) $E c C P D$ [43]. This type of effect, in similar proportions, was reported after replacing the fourth Trp of an animal (6-4) photolyase by a Phe $[37,44]$.

Here, we specifically dwell on the NewPHL from Dinoroseobacter shibae (DsNewPHL), a facultative anaerobic and anoxygenic photoheterotroph. Our scope focuses on the first FAD photoreduction step in DsNewPHL, which we studied by a combination of transient absorption spectroscopic

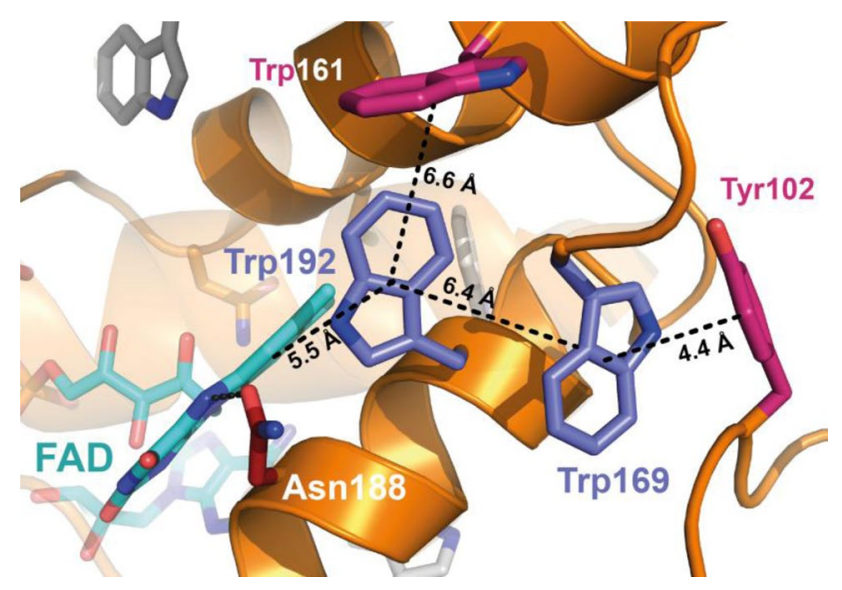

Fig. 1 View of the $D s$ NewPHL structure at the flavin binding site, as derived from a homology model of the protein [40], taking the Anacystis nidulans class I CPD photolyase (PDB entry 1TEZ) as a template. FAD is represented in cyan, the conserved tryptophan dyad $\left(\operatorname{Trp}_{192}, \operatorname{Trp}_{169}\right)$ of NewPHL in blue and the nearby residues $\operatorname{Tyr}_{102}$ and another tryptophan $\left(\operatorname{Trp}_{161}\right)$ in pink. Closest centroid-centroid distances between the aromatic moieties are indicated. $\mathrm{Asn}_{188}$ (red) is predicted to form a hydrogen-bond with the $\mathrm{N}_{5}$-nitrogen of the isoalloxazine moiety 
techniques covering timescales from hundred femtoseconds to microseconds.

\section{Materials and methods}

\subsection{Sample preparation of DsNewPHL}

The Dinoroseobacter shibae NewPHL (DsNewPHL) was prepared by recombinant overproduction in E. coli as previously reported [40]. Under standard aerobic conditions, the protein elutes in its semi-reduced form with its UV-Vis spectrum exhibiting the typical broad red band of FADH ${ }^{\bullet}$ [40]. The oxidized form of the protein was obtained by overnight incubation in the presence of potassium ferricyanide. The UV-Vis spectrum of DsNewPHL then shows the characteristic bands of $\mathrm{FAD}_{\text {ox }}$ [45], peaking here at 374 and $444 \mathrm{~nm}$ (see Figure S1 in Supplementary Information (SI), Section S1) [40]. Based on the ratio of the sample absorbance at $280 \mathrm{~nm}$ (protein $\left.+\mathrm{FAD}_{\mathrm{ox}}\right)$ and $444 \mathrm{~nm}\left(\mathrm{FAD}_{\mathrm{ox}}\right.$ alone), we estimated that the protein/flavin ratio is close to 1. Concentration over spin filters (Amicon Ultra-4, $30 \mathrm{kDa}$ cutoff) for femtosecond transient absorption measurements, as well as freezing and thawing, however induces moderate losses $(\leq 15 \%)$ of bound flavin.

The working buffer composition was: $50 \mathrm{mM}$ phosphate at $\mathrm{pH} 8.0,100 \mathrm{mM} \mathrm{NaCl}, 20 \%$ glycerol. $\mathrm{D}_{2} \mathrm{O}$ buffer was prepared by exchange with heavy water $(99.9$ atom \% D, Sigma-Aldrich) as previously described [32, 34].

\subsection{Femtosecond transient absorption spectroscopy (TAS)}

\subsubsection{Experimental conditions}

Polarized transient absorption spectra were recorded by the pump-probe technique, with a white-light continuum probe, as previously described $[32,34,39,46]$. The pump pulses (70 fs) were tuned at $470 \mathrm{~nm}$ using a two-stage noncollinear optical parametric amplifier (NOPA, Clark MXR). The energy used to excite the samples was $\sim 0.1 \mu \mathrm{J}$ per pulse, focused on a surface of $\sim 6100 \mu \mathrm{m}^{2}$ (at half of maximum). The fraction of excited molecules in the probed volume was estimated to $\sim 5-6 \%$ by calculation based on sample absorbance, pump energy and pump/probe transverse profiles [47], as well as comparison with a reference sample of tris- $\left(2,2^{\prime}-\right.$ bipyridyl)-ruthenium(II) complex [48, 49].

The $D s$ NewPHL samples were kept at $5{ }^{\circ} \mathrm{C}$ during the experiments with the help of a circulating thermostatic bath. Steady-state absorption spectra of the samples were regularly recorded during the experiments to check that no substantial degradation occurred. The samples, concentrated to $\sim 140 \mu \mathrm{MAD}_{\text {ox }}$ (see SI, Section S1), were held in 1-mm-path fused silica cells (FireflySci), continuously moving in two dimensions to avoid consecutive irradiation of the same volume [39].

The polarized differential absorptions $\left(\Delta A_{\|}\right.$and $\Delta A_{\perp}$, not shown) were first corrected from the chirp of the probe beam, independently measured by recording cross-phase modulation [50] in the pure solvent. They were then used to calculate the isotropic transient absorptions $\left(\Delta A_{\text {iso }}\right)$ and transient anisotropy $(r)$ using the standard definitions of these quantities $[32,34,39]$. Note that rotational diffusion of $D s$ NewPHL as a whole is not expected to play any role in the anisotropy dynamics during the time $3.2 \mathrm{~ns}$ window of our measurements. Indeed, previous reports showed that the rotational diffusion time of other photolyases under comparable conditions is of the order several tens of ns (depending on glycerol content and temperature) [39, 51]. Given that the size of $D s$ NewPHL ( $47 \mathrm{kDa}$ ) is somewhat smaller than that of standard photolyases $(\sim 55-60 \mathrm{kDa})$, a small correction should be applied to the literature data (factor of at most $\sim 0.8$ ) but without changing the order of magnitude. The anisotropy dynamics presented below should thus be considered as characteristic of intrinsic changes within the protein.

\subsubsection{Kinetic analysis}

The ultrafast transient absorption data were globally fitted [52] to a sum of exponential functions, convoluted by a Gaussian function representing the instrument response function ( $180 \mathrm{fs}$, full width at half maximum; includes numeric broadening due to sampling $\geq 100 \mathrm{fs}$ ). Singular value decomposition [53] was applied to the data to ease the fitting procedure and to filter out noise. The fits were made simultaneously on the parallel and perpendicular data (not shown), sharing the same sum of exponentials. Effective fits of the isotropic or anisotropy data were deduced from them $[32,34,39]$.

The fits are here presented using the so-called evolutionassociated difference spectra (EADS) [52], which correspond to a virtual cascading model with unity quantum yield between one state and the following and conveniently summarize the dynamics of the isotropic data. The anisotropy dynamics is similarly represented by evolution-associated anisotropy spectra (EAAS), deduced from the polarized EADS [32, 34].

\subsubsection{Spectral analysis}

To analyze the spectral changes between consecutive EADS in terms of appearance and disappearance of certain photoproducts (namely the $\operatorname{TrpH}^{\bullet+}$ and $\operatorname{Trp}{ }^{\bullet}$ radicals), we used an approach where the $\mathrm{EADS}_{\mathrm{i}+1}-\left(1-\phi_{r}\right) \mathrm{EADS}_{\mathrm{i}}$ difference is fitted by a sum of contributions from photoproducts. To 
improve the quality of the fits, the shapes of reference spectra of the radicals [54] are slightly modified with the help of a shift and a scaling factor (see SI, Section S2.3). The details of that procedure have been reported elsewhere [32, 34]. Factor $\phi_{r}$, which is optimally adjusted in the process, is the fraction of transient population at the start of phase $i$ that undergoes ground-state recovery (by charge recombination as will be seen below).

\subsubsection{Anisotropy analysis}

The anisotropy dynamics is essentially used here to monitor the origin of the $\operatorname{TrpH}^{\bullet+}$ or $\operatorname{Trp}{ }^{\bullet}$ spectral signatures. Since several residues may contribute at this wavelength, the anisotropy can establish a difference between them based on their spatial orientation. As detailed in former works [32, 34, 39], the procedure first consists in choosing a proper monitoring wavelength at which the values of the EAAS, averaged over five nanometers, are taken (Table 2). For $\mathrm{TrpH}^{\circ+}$, we chose $600 \mathrm{~nm}$, which lies on the red side of the $\mathrm{TrpH}^{\bullet+}$ absorption band (see Figure S4 in SI, Section S2.3), to minimize the possible contribution of the reduced flavin radical $\left(\mathrm{FAD}^{\bullet-}\right)[55,56]$. For $\operatorname{Trp}^{\bullet}, 530 \mathrm{~nm}$ was preferred, based on a similar argument. The experimental anisotropies are then compared to simulated ones (Table 3), expected at the monitoring wavelength if only one specific tryptophanyl species were contributing at a time. The simulated anisotropies are calculated [51] from the angle between the transition dipole moments of $\mathrm{FAD}_{\text {ox }}\left(73^{\circ}\right.$ from $\mathrm{N}_{5} \mathrm{~N}_{10}$ axis [39]) at the excitation wavelength and that of $\operatorname{TrpH}^{\circ+}\left(107.7^{\circ}\right.$ from $\mathrm{C}_{3 \mathrm{a}} \mathrm{C}_{7 \mathrm{a}}$ axis[39]) or $\operatorname{Trp}{ }^{\bullet}\left(104^{\circ}\right.$ from $\mathrm{C}_{3 \mathrm{a}} \mathrm{C}_{7 \mathrm{a}}$ axis [51]) at the monitoring wavelength. The orientations of the different species were taken from our homology model of DsNewPHL (Fig. 1) [40].

A tentative correction of the calculated anisotropies is proposed in Table 3 to take into account a possible minor contribution of $\mathrm{FAD}^{\bullet-}$ at the monitoring wavelength. Following the example of former works [32, 34], a maximum of $20 \%$ of the isotropic transient absorption at $600 \mathrm{~nm}$ is accepted to arise from $\mathrm{FAD}^{\bullet-}$ once charge separation has occurred. This number rises to $25 \%$, at $530 \mathrm{~nm}$, when $\mathrm{TrpH}^{\bullet+}$ is replaced by Trp ${ }^{\bullet}$ (Figure S4). The procedure also requires a value of the intrinsic anisotropy of (pure) $\mathrm{FAD}^{\bullet-}$ at the monitoring wavelength, which is here assumed to be the mean of two previously reported values $(-0.2$ [34] and $-0.1[32])$, that is, -0.15 . It should be noted that this approximate correction is merely intended to give an idea of the possible effect of $\mathrm{FAD}^{\bullet-}$ contribution to the predictions.

\subsection{Real-time TAS}

The real-time transient absorption setup has been described in detail elsewhere [35, 49, 57]. Two different pulsed lasers were used as excitation sources: Continuum Leop-

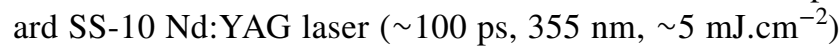
and Nd:YAG-pumped optical parametric oscillator (OPO;

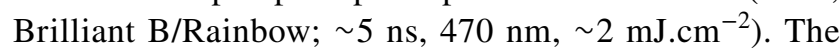
laser energy was estimated from energy measurements behind a cell filled with $\mathrm{H}_{2} \mathrm{O}$ using an energy meter (Gentec QE25SP-H-MB-D0) and from transient absorption signals using $\left[\mathrm{Ru}(\mathrm{bpy})_{3}\right]^{2+}$ as an actinometer [58]. Monitoring light at six selected wavelengths $(376,457,488,515,562$ and $690 \mathrm{~nm}$ ) was provided by continuous-wave lasers and a laser diode (Toptica iBeam smart 375-S, Cobolt Twist ${ }^{\mathrm{TM}}$, Picarro Cyan-20, Cobolt Fandango ${ }^{\mathrm{TM}}$, Oxxius 561-25-COL-002 and Ondax TO-690-PLR45, respectively). The measuring light was perpendicular to the excitation laser beam and passed through the sample along the $10-\mathrm{mm}$ path of a $2 \times 2 \times 10 \mathrm{~mm}$ $(\mathrm{W} \times \mathrm{H} \times \mathrm{L})$ quartz cell with self-masking solid black walls (Starna). Flash-induced changes of the transmission of the sample were monitored behind the sample by a Si photodiode (Alphalas UPD-200-UP, 200 ps rise time) coupled to a digital oscilloscope (Agilent Infinium 81004B, $10 \mathrm{GHz}$, or Tektronics MSO 64, $200 \mathrm{MHz}$,). The samples were kept at $5{ }^{\circ} \mathrm{C}$ during the measurements and the stock on ice.

Real-time transient absorption kinetics were determined using Levenberg-Marquardt least-squares optimization algorithm in Origin 2020 (by OriginLab), fitting the trend lines according to the equation: $y(t)=A \times e^{-t / \tau}+y_{0}$ or $y(t)=A_{1} \times$ $e^{-t / \tau 1}+A_{2} \times e^{-t / \tau 2}+y_{0}$ (global fits of all recorded signals).

\section{Results}

\subsection{Early photo-induced behavior of DsNewPHL}

\subsubsection{Spectral evolution}

Selected isotropic transient absorption spectra of DsNewPHL in $\mathrm{H}_{2} \mathrm{O}$ buffer, recorded between 200 fs and $3.2 \mathrm{~ns}$ after fs excitation at $470 \mathrm{~nm}$, are shown in Fig. 2(AC). The shapes of the earliest spectrum - with ground-state bleaching (GSB) at $444 \mathrm{~nm}$, stimulated emission (SE) at $539 \mathrm{~nm}$ and transient absorption (TA) bands at $364 \mathrm{~nm}$, $507 \mathrm{~nm}$ and beyond $\sim 600 \mathrm{~nm}$ - are well-characterized features of excited $\mathrm{FAD}_{\text {ox }}$ (here noted FAD*), often reported in other photolyases or cryptochromes [25, 32, 34, 39, 46], as well as free $\mathrm{FAD}_{\mathrm{ox}}$ in solution [24, 59].

The subsequent evolution, from 0.2 to 3.4 ps (Fig. 2a), with decay of the SE and red TA bands and growth of a new positive band around $580 \mathrm{~nm}$, have also been abundantly described $[25,32,34,39,46]$. It is assigned to the transfer of an electron from a Trp residue due to the FAD*, producing the $\mathrm{FAD}^{\bullet-} / \mathrm{TrpH}^{\bullet+}$ radical pair. $\mathrm{FAD}^{\bullet-}$ still strongly absorbs in the UV TA region, at $367 \mathrm{~nm}$, but shows a secondary peak at $400 \mathrm{~nm}[55,56,60]$, while 


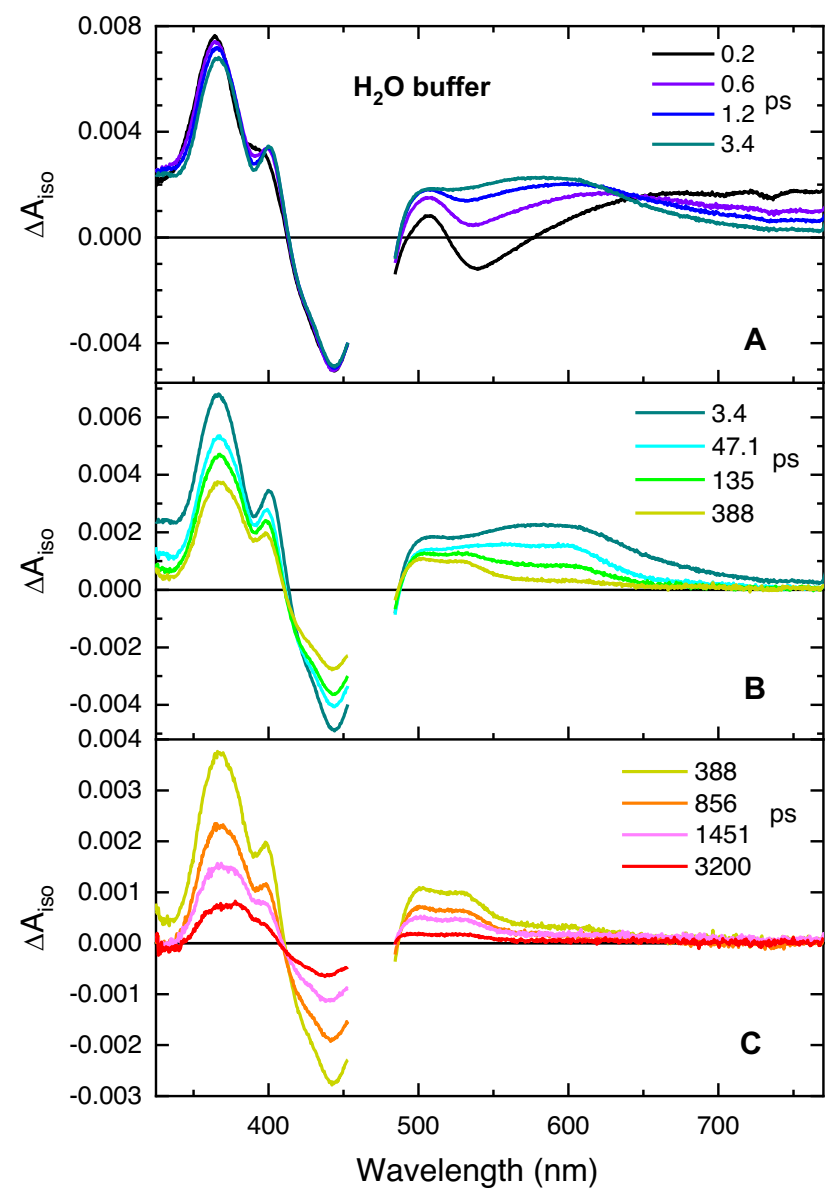

Fig. 2 Isotropic transient absorption spectra of DsNewPHL in $\mathrm{H}_{2} \mathrm{O}$ buffer, at selected pump-probe delays after fs excitation at $470 \mathrm{~nm}$

$\mathrm{TrpH}^{\bullet+}$ is responsible for the broad 580-nm band [54]. Virtually no decay of the GSB band can be seen during this primary ultrafast phase.

A second evolution phase, between 3.4 and $\sim 400$ ps (Fig. 2b), sees a partial decay of the UV TA and GSB bands and an even more conspicuous decay of the 580-nm band, which nearly disappears, leaving a local maximum around $515 \mathrm{~nm}$. The disappearance of the 580-nm band comes to completion during the last phase, between $\sim 400$ and 3200 ps (Fig. 2c), during which one also observes a strong but still partial decay of all bands. The last phase is also characterized by a modification of the shape of the UV TA band, which becomes rounder, somewhat red shifted and loses its secondary peak at $400 \mathrm{~nm}$.

The transient absorption spectra of DsNewPHL in a deuterated buffer are provided in Figure S2 (SI, Section S2.1). They are qualitatively identical to those in $\mathrm{H}_{2} \mathrm{O}$ buffer, but the intermediate phase is significantly slower. One indeed observes that the remains of the $580-\mathrm{nm}$ band at $388 \mathrm{ps}$ pump-probe delay are significantly larger in $\mathrm{D}_{2} \mathrm{O}$ than in $\mathrm{H}_{2} \mathrm{O}$.

\subsubsection{Kinetic analysis}

We could satisfactorily fit the parallel and perpendicular transient absorption spectra of $D s$ NewPHL with a sum of four exponential components followed by a plateau. Figure $3 \mathrm{a}, \mathrm{c}$ displays the global fits corresponding to the measurements of Fig. $2\left(\mathrm{H}_{2} \mathrm{O}\right)$ and Figure $\mathrm{S} 2\left(\mathrm{D}_{2} \mathrm{O}\right)$, in terms of isotropic EADS (see Sect. 2.2.2). The same spectra, arbitrarily normalized at the maximum of the bleaching band (around $444 \mathrm{~nm}$ ) are also proposed in Figure S3 (SI, Section S2.2), to better appreciate the changes of their shape. The evolution phases sketched above are here clearly quantified. The initial excited-state decay occurs with a time constant of $0.62 \mathrm{ps}$ in $\mathrm{H}_{2} \mathrm{O}$ buffer. The intermediate regime is decomposed in two time constants, 13 ps and 94 ps in $\mathrm{H}_{2} \mathrm{O}$. It may be noted that the $13 \mathrm{ps}$ phase is mainly characterized by a substantial narrowing and structuring of the $580-\mathrm{nm}$ band, as previously reported in similar timescales for other PCSf members [32, 39]. The 94 ps phase carries most of the actual decay of the 580-nm band, mentioned above. The final kinetic phase occurs in 938 ps in $\mathrm{H}_{2} \mathrm{O}$.

Four independent measurements were actually made in $\mathrm{H}_{2} \mathrm{O}$ buffer and two in $\mathrm{D}_{2} \mathrm{O}$, yielding very close results. Table 1 gathers the mean time constants obtained upon global fitting these recordings, namely $0.66,13,93$ and 951 ps in $\mathrm{H}_{2} \mathrm{O}$ and $0.67,27,146$ and 1125 ps in $\mathrm{D}_{2} \mathrm{O}$. It appears then clearly that $\mathrm{H} / \mathrm{D}$ exchange has no effect on the first time component $\left(\tau_{1}\right)$ but substantially slows down the following two components, by a factors of $2.1\left(\tau_{2}\right)$ and 1.6 $\left(\tau_{3}\right)$. A less significant kinetic isotope effect (factor of 1.2) remains on the final component $\left(\tau_{4}\right)$. As alluded above, it also clearly appears that EADS4 has a much larger intensity around $580 \mathrm{~nm}$ in $\mathrm{D}_{2} \mathrm{O}$ buffer than in $\mathrm{H}_{2} \mathrm{O}$ (see "Discussion", Sect. 4.1.3).

\subsubsection{Anisotropy dynamics}

The raw transient anisotropy spectra, calculated from the polarized data are not shown but Fig. 3 displays typical evolution-associated anisotropy spectra (EAAS) coming for the global analysis procedure. The initial phase is here accompanied by very large changes between 500 and $650 \mathrm{~nm}$, essentially due to the decay of the negative SE band, substituted by a positive transient absorption band. The second phase is characterized by a clear change of anisotropy in the region around $580 \mathrm{~nm}$ where $\mathrm{TrpH}^{\bullet+}$ mostly contributes. The value jumps from - 0.08 in EAAS2 (mean value of four independent measurements in $\mathrm{H}_{2} \mathrm{O}$ buffer) to about +0.05 in EAAS3 (idem). During the third phase, the anisotropy beyond $550 \mathrm{~nm}$ becomes increasingly noisy due to the decay of the 580-nm isotropic band. The anisotropy of the remaining isotropic band around $515 \mathrm{~nm}$ however does not change much during the third phase. During the final kinetic phase, 


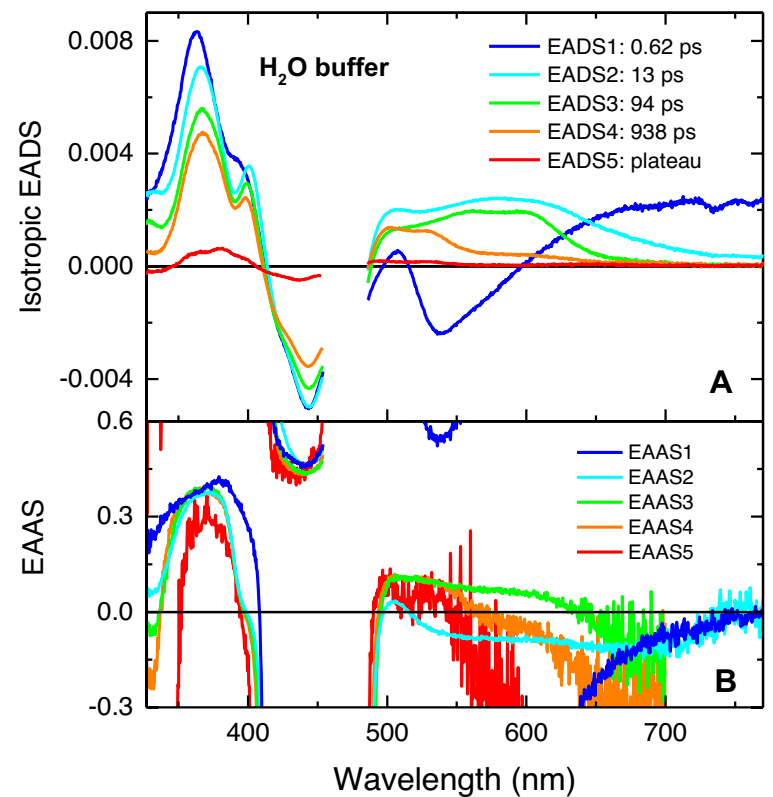

Fig. 3 Top: Isotropic EADS deduced from the global analysis of the polarized transient absorption spectra of DsNewPHL (a: in $\mathrm{H}_{2} \mathrm{O}$ buffer; $\mathbf{c}$ : in $\mathrm{D}_{2} \mathrm{O}$ buffer) with a sum of 4 exponentials and a plateau.

Table 1 Mean time constants calculated from the global multiexponential fits of four independent polarized transient absorption experiments of $D s$ NewPHL in $\mathrm{H}_{2} \mathrm{O}$ buffer and two such experiments in $\mathrm{D}_{2} \mathrm{O}$ buffer

\begin{tabular}{lllccl}
\hline Buffer & $<\tau_{1}>(\mathrm{ps})$ & $<\tau_{2}>(\mathrm{ps})$ & $<\tau_{3}>(\mathrm{ps})$ & $<\tau_{4}>(\mathrm{ps})$ & $\begin{array}{l}\text { Avg. } \\
\text { residue }\end{array}$ \\
\hline $\mathrm{H}_{2} \mathrm{O}$ & $0.66 \pm 0.08$ & $13 \pm 1$ & $93 \pm 4$ & $951 \pm 23$ & $61 \times 10^{-6}$ \\
$\mathrm{D}_{2} \mathrm{O}$ & $0.67 \pm 0$ & $27 \pm 3$ & $146 \pm 26$ & $1125 \pm 11$ & $54 \times 10^{-6}$ \\
\hline
\end{tabular}

The standard deviation is indicated after the \pm sign. The average residue of the fits is given in the last column

the anisotropy becomes unreliable above $550 \mathrm{~nm}$ because the corresponding isotropic spectra (denominator in the definition of $r$ ) nearly vanish.

\subsection{Fate of the remaining transient absorption changes followed by real-time TAS}

Real-time TAS signal recorded for $D s$ NewPHL $\left(\right.$ in $\mathrm{H}_{2} \mathrm{O}$ ) at $457 \mathrm{~nm}$ on a setup with $200 \mathrm{ps}$ time resolution (Figure S6 in SI, Section S3) captured the last ( 950 ps) kinetic phase observed in the ultrafast experiment and the decay of most $(>80 \%)$ of the initial transient absorption signal. Note that the initial signal amplitude (at $t \rightarrow 0$ ) is slightly underestimated because the processes faster than 200 ps could not be resolved in this experiment.

Evolution of the remaining transient absorption change on the nanosecond timescale (i.e. beyond the red spectrum

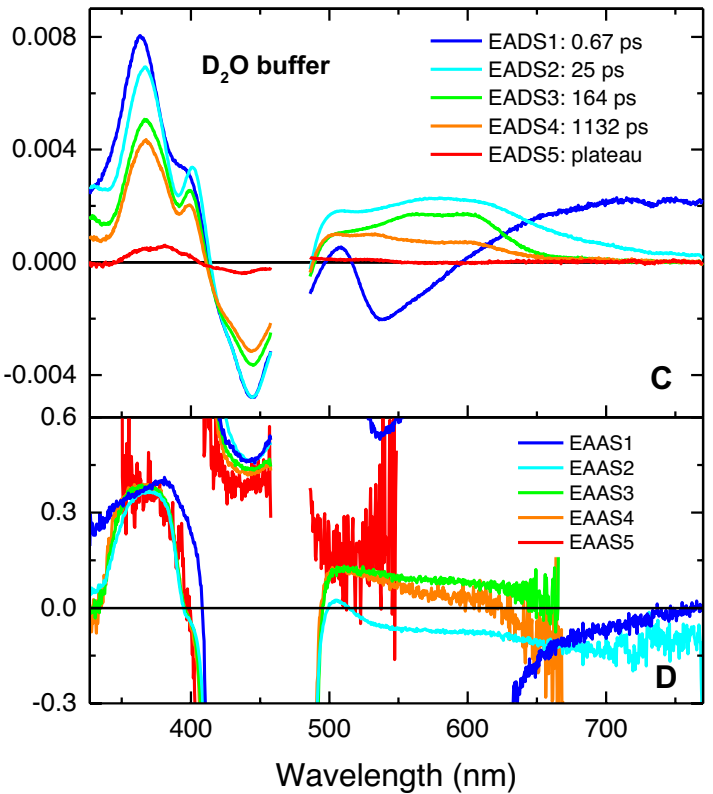

Bottom: Corresponding EAAS (b: in $\mathrm{H}_{2} \mathrm{O}$ buffer; $\mathbf{d}$ : in $\mathrm{D}_{2} \mathrm{O}$ buffer). Exceedingly noisy parts of these spectra have been masked

in Fig. 2) was followed using a more sensitive real-time TAS setup with a time resolution limited to $\sim 5 \mathrm{~ns}$ (excitation pulse duration). Transient absorption signals recorded at six selected monitoring wavelengths (Fig. 5a) show that, following the ultrafast processes discussed above and reflected by the (not well resolved) initial sharp peaks in Fig. 5a, the remaining TA signals decay almost entirely with common kinetics of $\sim 50 \mathrm{~ns}$. An exception is the signal at $690 \mathrm{~nm}$, which is essentially zero from the very beginning and does not exhibit any significant evolution on this timescale. Comparison of the relative amplitudes of the sub-ns phase and the $\sim 50$ ns phase (Fig. 5b) suggests that both processes reflect decays of spectrally identical species.

The small absorption change remaining after the $\sim 50 \mathrm{~ns}$ phase has a spectrum (Figure S7B) compatible with the triplet state of FAD [61] and its lifetime (1.2 $\mu$ s; Figure S8 in SI, Sect. 3) matches approximately that reported for the FAD triplet in solution $(\sim 3 \mu$ s [61]). Since its amplitude was seen to increase slightly when the sample was stored overnight at $0{ }^{\circ} \mathrm{C}$, we assign it to a small population of free FAD released by the protein as it slowly degrades. This signal is therefore not considered as part to the photo-induced response of $D s$ NewPHL.

We finally note that a minute residual absorption change $(<0.5 \mathrm{mOD}$ at $457 \mathrm{~nm})$ may be observed after the decay of the FAD triplet state, lasting for tens of microseconds (Figure S8). Given the amplitude of the signal even close to the maximum of FAD bleaching was very small, we did not attempt a closer spectral characterization of this residual 
Table 2 Evolution-associated anisotropies (EAAS) taken at $600 \mathrm{~nm}$ for EAAS2 $\left(r_{2}\right)$ and $\operatorname{EAAS} 3\left(r_{2}\right)$, and at $530 \mathrm{~nm}$ for EAAS4 $\left(r_{4}\right)$ and $\operatorname{EAAS5}\left(r_{5}\right)$

\begin{tabular}{lllll}
\hline Buffer & $r_{2}$ & $r_{3}$ & $r_{4}$ & $r_{5}$ \\
\hline $\mathrm{H}_{2} \mathrm{O}$ & $-0.08 \pm 0.01$ & $0.05 \pm 0.02$ & $0.12 \pm 0.03$ & $0.08 \pm 0.10$ \\
$\mathrm{D}_{2} \mathrm{O}$ & $-0.08 \pm 0.01$ & $0.09 \pm 0.03$ & $0.09 \pm 0.03$ & $0.21 \pm 0.01$ \\
\hline
\end{tabular}

The values have been first averaged over $5 \mathrm{~nm}$ and the mean value of the various independent experiments recorded in each buffer taken. The corresponding standard deviation is indicated after the \pm sign

Table 3 Simulated anisotropies of different $\operatorname{TrpH}^{\bullet+}$ or $\operatorname{Trp}{ }^{\bullet}$ radicals of the photoreduction chain at the monitoring wavelength $(600 \mathrm{~nm}$ for $\mathrm{TrpH}^{\bullet+}$ and $530 \mathrm{~nm}$ for Trp ${ }^{\bullet}$ ), according to our homology structure of DsNewPHL (Fig. 1) [40]

\begin{tabular}{lllll}
\hline Species & calculation & $\operatorname{Trp}_{192}$ & $\operatorname{Trp}_{169}$ & $\operatorname{Trp}_{161}$ \\
\hline $\mathrm{TrpH}^{\bullet+}$ & raw & $-0.03 \pm 0.07$ & $0.13 \pm 0.08$ & $0.30 \pm 0.02$ \\
& corrected & $-0.05 \pm 0.07$ & $0.08 \pm 0.08$ & $0.21 \pm 0.02$ \\
$\mathrm{Trp}^{\bullet}$ & raw & $0.00 \pm 0.08$ & $0.17 \pm 0.08$ & $0.30 \pm 0.02$ \\
& corrected & $-0.03 \pm 0.08$ & $0.09 \pm 0.08$ & $0.19 \pm 0.02$ \\
\hline
\end{tabular}

Errors indicated after the values correspond to variations of $\pm 5^{\circ}$ of the directions of both flavin and tryptophanyl transition moments within the molecular plane. The line entitled "corrected" proposes a tentative correction of the raw values, based on a hypothetical contribution of $\mathrm{FAD}^{\bullet-}$ at the monitoring wavelength (see Sect. 2.2.4)

species but we do not exclude that it could constitute a minor long-lived decay channel belonging to the photo-induced response of $D s$ NewPHL.

\section{Discussion}

\subsection{Ultrafast photoreduction steps}

\subsubsection{Primary flavin reduction}

As mentioned in Sect. 3.1, the transient absorption spectra show without ambiguity that the first phase in the photoreduction of oxidized $D s N e w P H L$ in vitro is the transfer of an electron from a Trp residue to the excited flavin, with a time constant of $0.66 \mathrm{ps}$. This is quite a standard behavior in most oxidized PCSf members [17, 24, 25, 32, 39], although a much longer time constant ( 9 ps) has been reported for the same reaction type of a class II CPD photolyase, which depends on a totally different tryptophan triad for ET [34]. The charge separation yield of this phase is assumed to be 1 in $D s$ NewPHL on the basis of its extremely fast rate, efficiently preventing any ground-state recovery. This is in line with the virtual absence of decay of the GSB band, although this indicator is not fully reliable since the GSB band is highly overlapped with the transient absorption of the flavin, which evolves from FAD* to FAD ${ }^{\bullet-}$.

The electron donor involved in phase 1 is most presumably the proximal Trp, which in the case of DsNewPHL and according to our homology model (Fig. 1) [40], is $\operatorname{Trp}_{192}$. $\operatorname{Trp}_{192}$ is predicted to be located at an centroid-to-centroid distance of $5.5 \AA$ (edge-to-edge $4.6 \AA$ ) from the isoalloxazine core of FAD and corresponds structurally to proximal tryptophans of other PCSf members apart the class II photolyases. Its assignment may be semi-quantitatively confirmed by examining the anisotropy at $600 \mathrm{~nm}$, dominated by the $\mathrm{TrpH}^{\bullet+}$ contribution, according to the procedure outlined in Sect. 2.2.4. The value of EAAS2, i.e. at the end of the $0.66 \mathrm{ps}$ phase, at this wavelength is $-0.08\left(r_{2}\right.$, Table 2$)$ while the simulated anisotropy for $\operatorname{Trp}_{192} \mathrm{H}^{\bullet+}$ is $-0.03(-0.05$ with tentative $\mathrm{FAD}^{\bullet-}$ correction; Table 3 ). Given the rather larger error on the prediction (see Table 3), it can be said that the experimental and theoretical values are essentially compatible. It may further be noted that the anisotropy attributed to the proximal $\operatorname{Trp}_{192} \mathrm{H}^{\bullet+}\left(r_{2}\right)$ is very similar to previously reported values $(\sim 0.06)$ for structurally analogous radicals (in canonical proximal position) in Xenopus laevis (6-4) photolyase [39] and Chlamydomonas rheinhardtii animallike cryptochrome [32].

It may also be recalled that the isotropic EADS2 shows a quite broad spectral signature of $\operatorname{TrpH}{ }^{\bullet+}$, extending well over $650 \mathrm{~nm}$ (Fig. 3 or Figure S3). Such a shape, which is significantly broader than that of $\operatorname{TrpH}^{\bullet+}$ in solution [54], has previously been reported for other PCSf members [25, 32, 39] and has been associated to the oxidized proximal Trp. The particular shape of EADS2 could be tentatively explained by the fact that the $\mathrm{TrpH}^{\bullet+}$ radical produced immediately after the initial ultrafast ET is in a hot vibrational state [25]. Alternatively, one might hypothesize that the proximal tryptophanyl radical would have a distinct absorption spectrum because of its close electrostatic interaction with the anionic flavin radical $\left(\mathrm{FAD}^{\bullet-}\right)$.

\subsubsection{Hole transport}

The second kinetic phase reported in Sect. 3.1.2, with a time constant of $13 \mathrm{ps}$, sees a clear narrowing of the $\operatorname{TrpH} \mathrm{H}^{\bullet+}$ absorption signature around $580 \mathrm{~nm}$ upon the transition from EADS2 to EADS3 (see Fig. 3 or Figure S3). Following the comment made above, this change might either be due to some vibrational cooling of the tryptophanyl radical or to a migration of the oxidation site away from the proximal Trp.

The anisotropy analysis provides here valuable information. One can indeed see in Table 2 that the value of EAAS3 at $600 \mathrm{~nm}\left(r_{3}\right)$ is 0.05 (in $\mathrm{H}_{2} \mathrm{O}$ buffer; 0.09 in $\mathrm{D}_{2} \mathrm{O}$ ), which is closer this time to the simulated anisotropy of $\operatorname{Trp}_{169} \mathrm{H}^{\bullet+}$, namely $0.13\left(0.08\right.$ with FAD $^{\bullet-}$ correction; Table 3$)$. Within the prediction errors and the uncertain 
reliability of our homology model of DsNewPHL, this can be taken as strong support to the hypothesis of electron hole migration, from $\operatorname{Trp}_{192} \mathrm{H}^{\bullet+}$ to $\operatorname{Trp}_{169}$. It is interesting in this respect to observe that $\operatorname{Trp}_{169}$ is not the only close aromatic residue to $\operatorname{Trp}_{192}$, as $\operatorname{Trp}_{161}$ has a centroidto-centroid distance of $6.6 \AA$ (edge-to-edge $3.7 \AA$ ) that is comparable to the $6.4 \AA$ for $\operatorname{Trp}_{169}$ (Fig. 1; edge-toedge $4.2 \AA$ ). The simulated anisotropy of $\operatorname{Trp}_{161} \mathrm{H}^{\bullet+}$ is however much larger $\left(0.30,0.21\right.$ with $\mathrm{FAD}^{\bullet-}$ correction; Table 3) and less compatible with the value of EAAS3 at $600 \mathrm{~nm}$. Till a crystal structure of a NewPHL becomes available one may currently hypothesize that the migration of the positive charge preferentially goes in the direction of $\operatorname{Trp}_{169}$. This preference might arise from the spatial arrangement of $\operatorname{Trp}_{192}$ and $\operatorname{Trp}_{169}$, which are predicted to share the same kind of long "border" between the proximal and medial tryptophan (Fig. 1) as other canonical PCSf members. The coplanar arrangement of their indole moieties potentially favors the overlap of donor-acceptor molecular orbitals and hence accelerates the ET rate. In contrast, the planes of the alternative pair $\operatorname{Tr} \mathrm{p}_{192}$-Trp $\mathrm{Tr}_{161}$ are essentially perpendicular in the NewPHL model. The polarity of the local environment of $\operatorname{Trp}_{169}$ might also be invoked, hypothetically, as a mean to favorably adjust the driving force and reorganization energy of the ET, as described within the Marcus theory [62, 63]. Theoretical approaches have proven feasible to quantify such effects and calculate ET rates in several PCSf members [64-66] and other flavoproteins [67-69]. They might be applied to $D s$ NewPHL, once a crystal structure is resolved, to check this hypothesis further.

It should be noted from Fig. 3 that phase 2 is accompanied by a moderate decay of the GSB and UV TA bands, interpreted as a partial charge recombination of the $\mathrm{FAD}^{\bullet-} / \operatorname{Trp}_{192} \mathrm{H}^{\bullet+}$ pair, in competition with the migration of the positive charge. The recombination yield of this phase is evaluated to about $13 \%$ (of the transient population in EADS2) from the loss of GSB intensity.

Last but not least, one may recall that phase 2 demonstrates a clear H/D kinetic isotope effect (KIE) of 2.1. This is quite large and unexpected for a reaction that would merely involve forward, and possibly backward, ET steps. One possible explanation could be that some proton transfer is also involved during this kinetic phase, as will be seen for the following phase, although such a process does not clearly show up in the transient absorption spectra. One could alternatively propose that H/D exchange in the buffer has an indirect impact on the protein, e.g. by changing the strength of the $\mathrm{H}$ bonds [70], possibly due to water molecules entering deeply into the core of the protein and participating in its structure. Distances might thereby be altered, to which ET rates are known to be highly sensitive [63].

\subsubsection{Tryptophanyl deprotonation}

The third kinetic phase occurs in 93 ps and is characterized by a strong decay of the $580 \mathrm{~nm}$ band (Fig. 3 and Figure S3), leaving a residual band around $515 \mathrm{~nm}$ and accompanied a further partial decay of the GSB and UV TA bands. Similar spectral evolutions have already been described for different oxidized PCSf members, in the context of tryptophanyl deprotonation after charge separation [20, 34, 35, 37]. This process typically takes place in the hundred ns regime $[5$, $20,37]$ in canonical PCSf members, but has been reported to occur in $\sim 300$ ps in a class II CPD photolyase [34, 35].

We here confirmed the involvement of tryptophanyl deprotonation during phase 3 using the spectral fitting approach sketched in Sect. 2.2.3. For that purpose, EADS4 was satisfactorily fitted with a sum of EADS3 and a difference of $\operatorname{TrpH}^{\bullet+}$ and $\operatorname{Trp}^{\bullet}$ absorption spectra taken from the literature and slightly modified to take into account spectral shifts and variations of width. The fit is shown in Fig. 4, while the optimized parameters and modified radical spectra may be found in SI, Section S2.3. We find that the yield of charge recombination $\left(\phi_{\mathrm{r}}\right)$ during phase 3 is $\sim 15 \%$ of the transient population in EADS3 (13\% of the transient population in EADS2) in $\mathrm{H}_{2} \mathrm{O}$ buffer and $\sim 13 \%$ in $\mathrm{D}_{2} \mathrm{O}$.

The yield of tryptophanyl deprotonation $\left(\phi_{\mathrm{d}}\right)$ during phase 3 is not directly provided by the spectral fit because the $\operatorname{TrpH}^{\bullet+}$ concentration at the start of the phase is not evaluated. This can however be estimated by analyzing the value of EADS3 in the red edge of the $\operatorname{TrpH}^{\bullet+}$ band (at $600 \mathrm{~nm}$ ), where the contribution of $\mathrm{FAD}^{\circ-}$ is minimal. The details of that calculation are provided in SI, Section S2.4. One finds that $\phi_{\mathrm{d}}$ is $\sim 79 \%$ of the transient population in EADS3 in $\mathrm{H}_{2} \mathrm{O}$ and $\sim 55 \%$ in $\mathrm{D}_{2} \mathrm{O}$. Interestingly, the lower value of $\phi_{\mathrm{d}}$ in $\mathrm{D}_{2} \mathrm{O}$, in line with a larger $\mathrm{TrpH}^{\bullet+}$ signature in EADS4 (Fig. 3c or Figure S3B), is

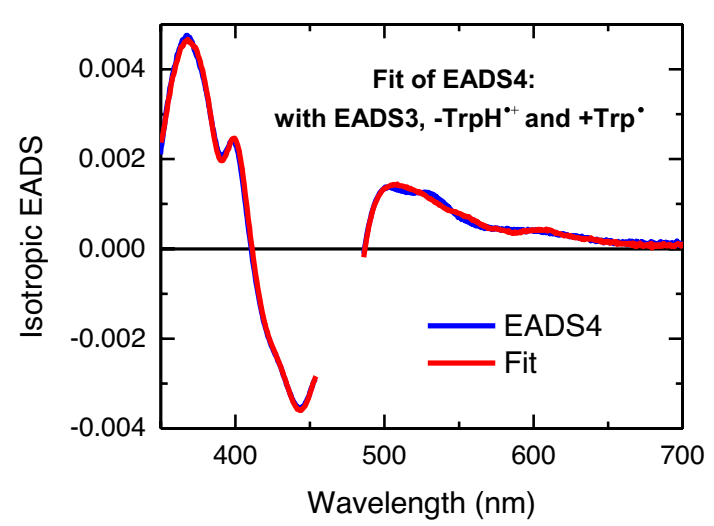

Fig. 4 Spectral fittings of EADS4 (DsNewPHL in $\mathrm{H}_{2} \mathrm{O}$ buffer) with a weighted sum of EADS3, $\operatorname{TrpH}^{\bullet+}$ (with negative sign) and $\operatorname{Trp}^{\bullet}$ (with positive sign) components (see details in Sect. 4.1.3 and SI, Section $\mathrm{S} 2.3)$ 


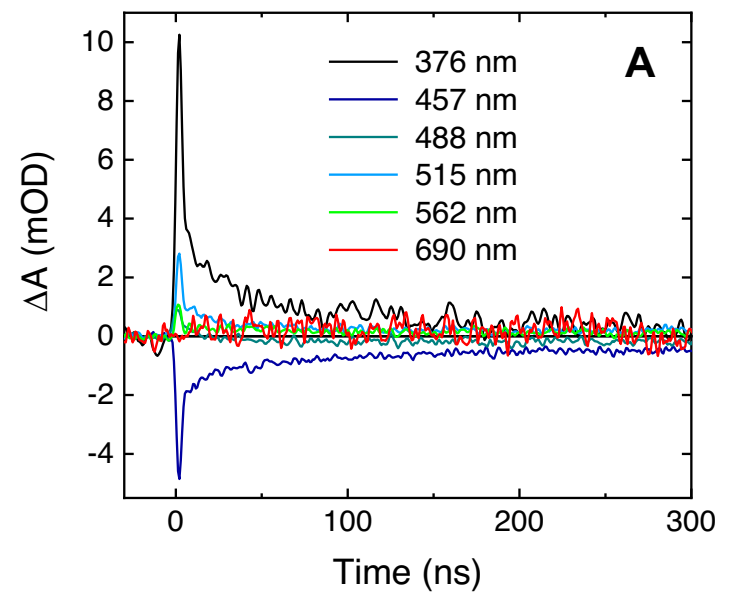

Fig. 5 a Flash-induced absorption changes on a ns timescale for $\sim 40 \mu \mathrm{M} D s$ NewPHL at six characteristic wavelengths. b Signal amplitudes at $t \rightarrow 0$ resulting from a bi-exponential global fit (see also Figure S6) for the sub-ns phase $A_{1}$ (not well resolved in this experiment) and the $\sim 50 \mathrm{~ns}$ phase $A_{2}$, compared to difference spectra

not due to a larger charge recombination yield. It appears that $\mathrm{TrpH}^{\bullet+}$ deprotonation is only partial in $\mathrm{D}_{2} \mathrm{O}$ during phase 3 , the completion of it taking place during phase 4 (see below), with final decay of the $\operatorname{TrpH}^{\bullet+}$ band (better seen in Figure S3B). The meaning of this result is not clear to us but we imagine that, if solvation in the $\mathrm{D}_{2} \mathrm{O}$ buffer leads to small structural changes with respect to the structure in the $\mathrm{H}_{2} \mathrm{O}$ buffer, $\operatorname{Trp}_{161}$ could participate in ET to a larger extent in $\mathrm{D}_{2} \mathrm{O}$ - note that the value of $r_{5}$ is rather different in $\mathrm{H}_{2} \mathrm{O}(0.08)$ and $\mathrm{D}_{2} \mathrm{O}(0.21)$ and that $r_{5}$ in $\mathrm{D}_{2} \mathrm{O}$ fits the corrected simulated anisotropy of $\operatorname{Trp}_{161}{ }^{\circ}$ (0.19) better than that of $\operatorname{Trp}_{169}{ }^{\bullet}(0.09)$.

The discussion of Sect. 4.1.2 suggests that the tryptophanyl undergoing deprotonation during kinetic phase 3 is essentially $\operatorname{Trp}_{169} \mathrm{H}^{\bullet+}$. This assignment is supported by the anisotropy observed in EAAS4 $\left(r_{4}\right.$, Table 2$)$ at $530 \mathrm{~nm}$, where the contribution of $\operatorname{Trp}{ }^{\bullet}$ is dominant (see Figure S4). One finds 0.12 (in $\mathrm{H}_{2} \mathrm{O}$ buffer; 0.09 in $\mathrm{D}_{2} \mathrm{O}$ ), which is not far within errors from the simulated anisotropy of $\operatorname{Trp}_{169}{ }^{\circ}$ (between 0.17 and 0.09 , Table 3). The possible contribution of $\operatorname{Trp}_{161}{ }^{\bullet}$ is thus at this stage not favored in the $\mathrm{H}_{2} \mathrm{O}$ buffer.

The nature of the primary proton acceptor involved in this kinetic phase is at the moment not identified. We may however conceive that a cluster of protein-bound water molecules could potentially play this role, as was previously reported for the class II CPD photolyase mentioned above [35], as its tryptophanyl deprotonation is also unusually fast. However, this hypothesis requires confrontation with a high-resolution crystal structure of a NewPHL protein.

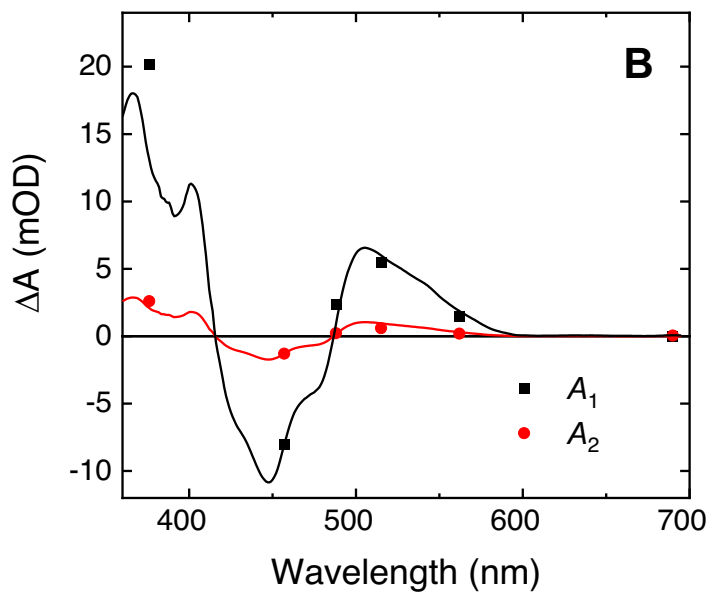

FAD $^{\bullet-}+\operatorname{Trp}^{\bullet}-\mathrm{FAD}_{\text {ox }}$ used in Ref. [37] (normalized to pass through the points at $457 \mathrm{~nm}$ ). The sample was excited at $470 \mathrm{~nm}$ by pulses of $\sim 5 \mathrm{~ns}$ duration and an energy of $\sim 2 \mathrm{~mJ}$ and a size of approximately $1 \mathrm{~cm}^{2}$. Individual traces are averages of 64 signals recorded with a frequency of $2 \mathrm{~Hz}$

\subsubsection{Charge recombination and stabilization}

We have seen in previous sections that charge recombination of the $\mathrm{FAD}^{\bullet-} / \mathrm{TrpH}^{\bullet+}$ pair occurs during the second and third kinetic phases (13 and 93 ps in $\mathrm{H}_{2} \mathrm{O}$ buffer), with successive yields of about $13 \%$ and $15 \%$, respectively. A much larger degree of charge recombination is observed during the fourth phase ( $951 \mathrm{ps)}$ ). Using the decay of the GSB maximum between EADS4 and EADS5, one calculates a yield of charge recombination of $86 \%$ of the transient population in EADS4 (64\% of the transient population in EADS2) for that phase alone. Overall, the successive recombination steps represent $13 \%, 13 \%$ and $64 \%$ of the initial charge-separated population (in EADS2). Including all three steps, the total yield of charge recombination amounts to $90 \%$. As previously commented for other photolyases [17, $34,39]$, it is likely that fast charge recombination during the sub-ns phases actually takes place from the proximal $\mathrm{FAD}^{\bullet-} / \mathrm{TrpH}^{\bullet+}$ pair (because the radicals are here separated by a shorter, more favorable distance) that would be weakly repopulated by some back electron/proton transfers - presently unresolved.

The fourth kinetic phase ( $950 \mathrm{ps})$ is characterized by a marked modification of the UV transient absorption band, which develops a maximum at $380 \mathrm{~nm}$ in EADS5, while EADS4 peaks at $367 \mathrm{~nm}$ (better seen in Figure S3). The red shoulder of this band also seems to be significantly altered as one observes that the maximum of the GSB band shifts from 444 to $436 \mathrm{~nm}$. The exact origin of these spectral changes is not clear to us but one may hypothesize that they arise from changes in the hydrogen bonding network around the 
flavin. For instance, a similar spectral change (narrowing down, shift and diminishing of the FAD ${ }^{\bullet-} \mathrm{UV}$ band and shift of the shoulder in the visible) was reported for the N378D mutant of EcCPD upon photoreduction of an artificially fully oxidized FAD cofactor [20]. The authors suggested that unlike in most other photolyases and cryptochromes, FAD $^{\bullet-}$ does not get protonated in this particular case (or only to a very small extent) and is stabilized by mere hydrogen bonding to the neighboring amino acid instead. In the case of $D s$ NewPHL, one can imagine that $\mathrm{FAD}^{\bullet-}$ could be stabilized by forming an H-bond, e.g. to the amide group of $\mathrm{N}_{188}$ side chain. It may be further supposed that such structural changes would help stabilizing the $\mathrm{FAD}^{\bullet-} / \mathrm{Trp}^{\bullet}$ pair radical, possibly by slowing down some back ET channels involved in charge recombination.

\subsection{Final charge recombination step}

Global bi-exponential fit of all data, shown in Figure S7A, yielded time constants of $\sim 2 \mathrm{~ns}$ and $\sim 50 \mathrm{~ns}$. The $\sim 2 \mathrm{~ns}$ phase actually corresponds to the $\sim 950$ ps phase reported above, which was not well resolved by the real-time TAS setup used here. Plotting the amplitudes of the individual phases against wavelength and comparing them with the combined spectra of FAD and Trp radical species from the literature suggest that both processes reflect the recombination of $\mathrm{FAD}^{\bullet-} / \mathrm{Trp}^{\bullet}$ radical pairs (Fig. 5b and S7B). It is however unclear, whether the biphasic characteristics of this process is due to recombination of $\mathrm{FAD}^{\bullet-}$ with a heterogeneous mixture of two different $\operatorname{Trp}{ }^{\bullet}$ species (e.g. majority of $\operatorname{Trp}_{169}{ }^{\bullet}$ and minority of $\operatorname{Trp}_{161}{ }^{\circ}$ ) or due to a stabilization of one or both radicals in the $\mathrm{FAD}^{\bullet-} / \operatorname{Trp}_{169^{\circ}}$ pair during the $\sim 950$ ps phase. Study of mutants of $\operatorname{Trp}_{169}$ and $\operatorname{Trp}_{161}$, which is beyond the scope of the current paper, should provide an answer to this question. Theoretical approaches such as the ones alluded to above [64-69] might also provide clarifications on the precise mechanisms of charge recombination at work in DsNewPHL.

It is then interesting to establish a relation between the photo-induced response of oxidized $D s$ NewPHL observed here and its reported photoreduction in vitro [40]. The fastest decay component with which reduction by the external electron donor (50 mM DTT) could possibly compete is the $\sim 50 \mathrm{~ns}$ phase. For the sake of comparison, let us recall that the terminal radical recombination in other WT photolyases typically occurs on the ms timescale $[18,20,37$, 58], which leaves considerably more time for external reduction. The case of the W370F mutant of the (6-4) photolyase from Xenopus laevis (Xl64) is closer to DsNewPHL because its final charge recombination takes place in only $10 \mu \mathrm{s}$ [37], and its photoreduction is possible in vitro (with $6 \mathrm{mM}$ cysteine) [44] - yet highly impaired as compared to the WT protein. We however highlight that the decay of the FAD ${ }^{\bullet-} /$ Trp $^{\bullet}$ radical pair in Xl64-W370F is still 200 times slower than that in DsNewPHL and hence much more favorable to competition by external reduction. The decay of EcCPD-W306F ( 1 $\mu \mathrm{s}$, in semi-reduced form [42]) is only 20 times slower and, in that case, in vitro photoreduction was reported to be absent [41]. We therefore anticipate that external reduction in competition with the $\sim 50 \mathrm{~ns}$ phase of $D s$ NewPHL should be extremely inefficient, even at a DTT concentration of $50 \mathrm{mM}$. We rather suggest that in vitro photoreduction proceeds in competition with the very weak, longer-lived component that we could detect as residual $\mathrm{FAD}_{\mathrm{ox}}$ bleaching at 457 and $488 \mathrm{~nm}$ on the $\mu$ s timescale (Figure S8 and Sect. 3.2).

The efficiency of such a photoreduction channel is however doubtful in vivo, as the cytosolic reductant concentrations, diffusion conditions and intensity of available light (not absorbed by other present chromophores) are likely much less favorable than in the in vitro experiment [40]. The case of the (6-4) photolyase from Xenopus laevis (Xl64) illustrates this situation quite well: even though Xl64-W370F is still photoreducible and active for DNA repair in vitro, it has been found inactive for DNA repair in E. coli [44]. This was interpreted by the impairment of photoreduction in vivo, due to fast radical pair recombination $(10 \mu \mathrm{s})$ in this mutant -4000 times faster than in the WT [37].

\section{Conclusion}

We have shown that the photoreduction dynamics of oxidized $D s$ NewPHL begins similarly as that of canonical photolyases or cryptochromes, with a sub-ps primary reduction of the excited flavin by the adjacent $\operatorname{Trp}(0.7 \mathrm{ps}$ phase), followed by migration of the electron hole towards the second Trp in the tens of ps regime (13 ps phase), in competition with modest charge recombination. We then observed a very fast deprotonation of the $\operatorname{TrpH}^{\bullet+}$ radical, with a time constant of $\sim 90$ ps. This is more than three orders of magnitude faster than in any other canonical PCSf member [5, 20, 37] and still about three times faster than in the recently reported case of a non-canonical class II CPD photolyase [34, 35]. In spite of this unprecedentedly fast deprotonation, which helps stabilizing charge separation [43], charge recombination massively takes place in a subsequent $~ 950$ ps phase. Globally, 90\% of all photo-induced radical pairs are lost within a few nanoseconds and the remaining $\sim 10 \%$ is seen to almost fully disappear in less than $200 \mathrm{~ns}$ ( $\sim 50 \mathrm{~ns}$ phase). A very weak signal however remains on the $\mu$ s timescale, which could not be spectrally identified. Figure 6 summarizes the whole dynamics (the long-lived residual is not represented in this scheme because it is very weak and has insufficiently been resolved). Such a rapid and almost complete 


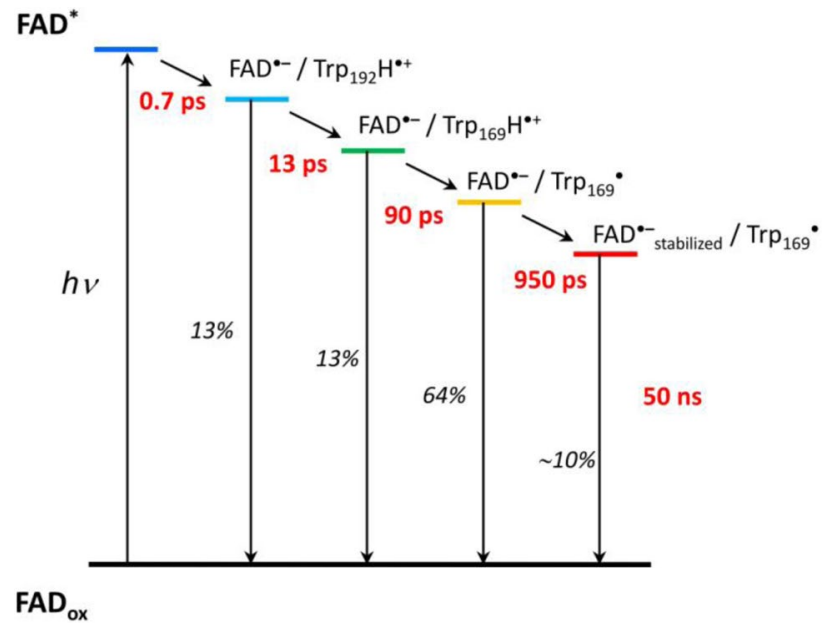

Fig. 6 Simplified reaction scheme for the photoreduction of oxidized $D s$ NewPHL in the $\mathrm{H}_{2} \mathrm{O}$ buffer. The time constants have been rounded. Note that charge recombination of the FAD ${ }^{\bullet-}$ and $\operatorname{Trp}_{169} \mathrm{H}^{\bullet+}$ or $\operatorname{Trp}_{169}$ radicals in the sub-ns timescale in fact likely proceed via partial repopulation of the $\mathrm{FAD}^{\bullet-} / \operatorname{Trp}_{192} \mathrm{H}^{\bullet+}$ state within a dynamic equilibrium, not resolved in the present study and not represented in this scheme. The fractions of the initial charge-separated state (EADS2) undergoing charge recombination at each step are indicated in italics. The weak, long-lived decay channel discussed in Sect. 4.2 is not represented in this scheme, due the weakness and uncertain nature of the corresponding transient absorption signals

recombination of the radical pairs in the ns timescale leaves virtually no time for extrinsic reductants to act upon the Trp radicals, or for extrinsic proton donors to stabilize FAD $^{\bullet-}$ in vivo, although the weak long-lived time decay component could explain the possibility of photoreduction in vitro [40]. We therefore conclude that the first photoreduction step, that is, conversion of fully oxidized FAD to the semi-quinone form $\mathrm{FADH}^{\bullet}$, should be essentially impossible in $D s$ NewPHL in vivo.

While this step is the basis of signaling by cryptochromes and the initial step in photoactivation of some photolyases $[37,44,57]$, we believe that it is unlikely to play any significant role in $D s$ NewPHL. This situation could be understood within the picture established for EcCPD by Payne et al. [71], namely that photoreduction is per se not required in vivo, i.e. in $E$. coli, because the flavin is already fully reduced in the dark. It could similarly be that the oxidation state of the flavin in DsNewPHL in the dark, within Dinoroseobacter shibae, would be either fully or semi-reduced. Notably, recombinant $D s \mathrm{NewPHL}$ contains $\mathrm{FADH}^{\bullet}$ when purified under aerobic conditions and the $\mathrm{FADH}^{-}$state when isolated under anaerobic conditions [40]. If that is the case in Dinoroseobacter shibae, the biologically relevant step leading to photoactivation of DNA repair [40] will be the second photoreduction step, from $\mathrm{FADH}^{\bullet}$ to $\mathrm{FADH}^{-}$. Spectroscopic characterization of the dynamics of this process will be subject of our future investigations.
Supplementary Information The online version contains supplementary material available at https://doi.org/10.1007/s43630-021-00048-4.

Acknowledgements The present work has benefited from the platform of Biophysics of I2BC supported by French Infrastructure for Integrated Structural Biology (FRISBI) ANR-10-INBS-05.

\section{Declarations}

Conflict of interest There are no conflicts to declare.

\section{References}

1. Sancar, A. (2003). Structure and function of DNA photolyase and cryptochrome blue-light photoreceptors. Chemical Reviews, 103(6), 2203-2237. https://doi.org/10.1021/cr0204348

2. Cadet, J., Sage, E., \& Douki, T. (2005). Ultraviolet radiation-mediated damage to cellular DNA. Mutation Research, 571(1-2), 3-17. https://doi.org/10.1016/j.mrfmmm.2004.09.012

3. Weber, S. (2005). Light-driven enzymatic catalysis of DNA repair: a review of recent biophysical studies on photolyase. Biochimica et Biophysica Acta - Bioenergetics, 1707(1), 1-23. https://doi.org/ 10.1016/j.bbabio.2004.02.010

4. Müller, M., \& Carell, T. (2009). Structural biology of DNA photolyases and cryptochromes. Current Opinion in Structural Biology, 19(3), 277-285. https://doi.org/10.1016/j.sbi.2009.05.003

5. Brettel, K., \& Byrdin, M. (2010). Reaction mechanisms of DNA photolyase. Current Opinion in Structural Biology, 20, 693-701. https://doi.org/10.1016/j.sbi.2010.07.003

6. Yamamoto, J., Plaza, P., \& Brettel, K. (2017). Repair of (6-4) lesions in DNA by (6-4) photolyase: 20 years of quest for the photoreaction mechanism. Photochemistry and Photobiology, 93(1), 51-66. https://doi.org/10.1111/php.12696

7. Ritz, T., Adem, S., \& Schulten, K. (2000). A model for photoreceptor-based magnetoreception in birds. Biophysical Journal, 78(2), 707-718. https://doi.org/10.1016/s0006-3495(00)76629-x

8. Cashmore, A. R. (2003). Cryptochromes: enabling plants and animals to determine circadian time. Cell, 114(5), 537-543. https:// doi.org/10.1016/j.cell.2003.08.004

9. Chaves, I., Pokorny, R., Byrdin, M., Hoang, N., Ritz, T., Brettel, K., Essen, L.-O., van der Horst, G. T. J., Batschauer, A., \& Ahmad, M. (2011). The cryptochromes: Blue light photoreceptors in plants and animals. Annual Review of Plant Biology, 62, 335-364. https://doi.org/10.1146/annurev-arplant-042110-103759

10. Hore, P. J., \& Mouritsen, H. (2016). The radical-pair mechanism of magnetoreception. Annual Review of Biophysics, 45, 299-344. https://doi.org/10.1146/annurev-biophys-032116-094545

11. Wang, Q., \& Lin, C. (2020). Mechanisms of cryptochromemediated photoresponses in plants. Annual Review of Plant Biology, 71, 103-129. https://doi.org/10.1146/annurev-arpla nt-050718-100300

12. Heelis, P. F., \& Sancar, A. (1986). Photochemical properties of Escherichia coli DNA photolyase: A flash photolysis study. Biochemistry, 25(25), 8163-8166. https://doi.org/10.1021/bi003 $73 \mathrm{a} 006$

13. Okamura, T., Sancar, A., Heelis, P. F., Hirata, Y., \& Mataga, N. (1989). Doublet-quartet intersystem crossing of flavin radical in DNA photolyase. Journal of the American Chemical Society, 111(15), 5967-5969. https://doi.org/10.1021/ja00197a082

14. Heelis, P. F., Okamura, T., \& Sancar, A. (1990). Excited-state properties of Escherichia coli DNA photolyase in the picosecond to millisecond time scale. Biochemistry, 29(24), 5694-5698. https://doi.org/10.1021/bi00476a008 
15. Aubert, C., Vos, M. H., Mathis, P., Eker, A. P. M., \& Brettel, K. (2000). Intraprotein radical transfer during photoactivation of DNA photolyase. Nature, 405(6786), 586-590. https://doi.org/10. $1038 / 35014644$

16. Lukacs, A., Eker, A. P. M., Byrdin, M., Brettel, K., \& Vos, M. H. (2008). Electron hopping through the 15 Angström triple tryptophan molecular wire in DNA photolyase occurs within 30 ps. Journal of the American Chemical Society, 130(44), 1439414395. https://doi.org/10.1021/ja805261m

17. Liu, Z. Y., Tan, C., Guo, X. M., Li, J., Wang, L. J., Sancar, A., \& Zhong, D. P. (2013). Determining complete electron flow in the cofactor photoreduction of oxidized photolyase. Proceedings of the National Academy of Sciences of the United States of America, 110(32), 12966-12971. https://doi.org/10.1073/pnas.1311073110

18. Byrdin, M., Lukacs, A., Thiagarajan, V., Eker, A. P. M., Brettel, K., \& Vos, M. H. (2010). Quantum yield measurements of shortlived photoactivation intermediates in DNA photolyase: Toward a detailed understanding of the triple tryptophan electron transfer chain. The Journal of Physical Chemistry A, 114(9), 3207-3214. https://doi.org/10.1021/jp9093589

19. Liu, Z. Y., Tan, C., Guo, X. M., Li, J., Wang, L. J., \& Zhong, D. P. (2014). Dynamic determination of active-site reactivity in semiquinone photolyase by the cofactor photoreduction. Journal of Physical Chemistry Letters, 5(5), 820-825. https://doi.org/10. 1021/jz500077s

20. Müller, P., Brettel, K., Grama, L., Nyitrai, M., \& Lukacs, A. (2016). Photochemistry of wild-type and N378D mutant E. coli DNA photolyase with oxidized FAD cofactor studied by transient absorption spectroscopy. ChemPhysChem, 17(9), 1329-1340. https://doi.org/10.1002/cphc.201501077.

21. Engelhard, C., Wang, X., Robles, D., Moldt, J., Essen, L.-O., Batschauer, A., Bittl, R., \& Ahmad, M. (2014). Cellular metabolites enhance the light sensitivity of Arabidopsis cryptochrome through alternate electron transfer pathways. The Plant Cell, 26(11), 4519-4531. https://doi.org/10.1105/tpc.114.129809

22. Ignatz, E., Geisselbrecht, Y., Kiontke, S., \& Essen, L. O. (2018). Nicotinamide adenine dinucleotides arrest photoreduction of class II DNA photolyases in $\mathrm{FADH}^{\bullet}$ state. Photochemistry and Photobiology, 94(1), 81-87. https://doi.org/10.1111/php.12834

23. Kao, Y. T., Tan, C., Song, S. H., Ozturk, N., Li, J., Wang, L. J., Sancar, A., \& Zhong, D. P. (2008). Ultrafast dynamics and anionic active states of the flavin cofactor in cryptochrome and photolyase. Journal of the American Chemical Society, 130(24), 7695-7701. https://doi.org/10.1021/ja801152h

24. Brazard, J., Usman, A., Lacombat, F., Ley, C., Martin, M. M., \& Plaza, P. (2011). New insights into the ultrafast photophysics of oxidized and reduced FAD in solution. The Journal of Physical Chemistry A, 115(15), 3251-3262. https://doi.org/10.1021/jp110 $741 \mathrm{y}$

25. Immeln, D., Weigel, A., Kottke, T., \& Perez Lustres, J. L. (2012). Primary events in the blue light sensor plant cryptochrome: Intraprotein electron and proton transfer revealed by femtosecond spectroscopy. Journal of the American Chemical Society, 134(30), 12536-12546. https://doi.org/10.1021/ja302121z

26. Biskup, T., Hitomi, K., Getzoff, E. D., Krapf, S., Koslowski, T., Schleicher, E., \& Weber, S. (2011). Unexpected electron transfer in cryptochrome identified by time-resolved EPR spectroscopy. Angewandte Chemie-International Edition, 50(52), 12647-12651. https://doi.org/10.1002/anie.201104321

27. Krapf, S., Weber, S., \& Koslowski, T. (2012). The road not taken: A theoretical view of an unexpected cryptochrome charge transfer path. Physical Chemistry Chemical Physics, 14(32), 1151811524. https://doi.org/10.1039/c2cp40793k

28. Aubert, C., Mathis, P., Eker, A. P. M., \& Brettel, K. (1999). Intraprotein electron transfer between tyrosine and tryptophan in DNA photolyase from Anacystis nidulans. Proceedings of the
National Academy of Sciences of the United States of America, 96, 5423-5427. https://doi.org/10.1073/pnas.96.10.5423

29. Giovani, B., Byrdin, M., Ahmad, M., \& Brettel, K. (2003). Lightinduced electron transfer in a cryptochrome blue-light photoreceptor. Nature Structural Biology, 10(6), 489-490. https://doi.org/10. 1038/nsb933

30. Biskup, T., Paulus, B., Okafuji, A., Hitomi, K., Getzoff, E. D., Weber, S., \& Schleicher, E. (2013). Variable electron transfer pathways in an amphibian cryptochrome. Journal of Biological Chemistry, 288(13), 9249-9260. https://doi.org/10.1074/jbc. M112.417725

31. Geisselbrecht, Y., Fruehwirth, S., Schroeder, C., Pierik, A. J., Klug, G., \& Essen, L.-O. (2012). CryB from Rhodobacter sphaeroides: A unique class of cryptochromes with new cofactors. EMBO Reports, 13(3), 223-229. https://doi.org/10.1038/embor. 2012.2

32. Lacombat, F., Espagne, A., Dozova, N., Plaza, P., Müller, P., Brettel, K., Franz-Badur, S., \& Essen, L.-O. (2019). Ultrafast oxidation of a tyrosine by proton-coupled electron transfer promotes light activation of an animal-like cryptochrome. Journal of the American Chemical Society, 141(34), 13394-13409. https://doi. org/10.1021/jacs.9b03680

33. Kiontke, S., Geisselbrecht, Y., Pokorny, R., Carell, T., Batschauer, A., \& Essen, L.-O. (2011). Crystal structures of an archaeal class II DNA photolyase and its complex with UV-damaged duplex DNA. EMBO Journal, 30(21), 4437-4449. https://doi.org/10. 1038/emboj.2011.313

34. Lacombat, F., Espagne, A., Dozova, N., Plaza, P., Ignatz, E., Kiontke, S., \& Essen, L.-O. (2018). Femtosecond transient absorption study of the primary photoreduction events of a class II photolyase. Physical Chemistry Chemical Physics, 20, 2544625457. https://doi.org/10.1039/C8CP04548H

35. Müller, P., Ignatz, E., Kiontke, S., Brettel, K., \& Essen, L. O. (2018). Sub-nanosecond tryptophan radical deprotonation mediated by a protein-bound water cluster in class II DNA photolyases. Chemical Science, 9(5), 1200-1212. https://doi.org/10.1039/c7sc0 $3969 \mathrm{~g}$

36. Scheerer, P., Zhang, F., Kalms, J., von Stetten, D., Krauß, N., Oberpichler, I., \& Lamparter, T. (2015). The class III cyclobutane pyrimidine dimer photolyase structure reveals a new antenna chromophore binding site and alternative photoreduction pathways. Journal of Biological Chemistry, 290(18), 11504-11514. https://doi.org/10.1074/jbc.M115.637868

37. Müller, P., Yamamoto, J., Martin, R., Iwai, S., \& Brettel, K. (2015). Discovery and functional analysis of a 4th electron-transferring tryptophan conserved exclusively in animal cryptochromes and (6-4) photolyases. Chemical Communications, 51, 1550215505. https://doi.org/10.1039/c5cc06276d

38. Nohr, D., Franz, S., Rodriguez, R., Paulus, B., Essen, L. O., Weber, S., \& Schleicher, E. (2016). Extended electron-transfer in animal cryptochromes mediated by a tetrad of aromatic amino acids. Biophysical Journal, 111(2), 301-311. https://doi.org/10. 1016/j.bpj.2016.06.009

39. Martin, R., Lacombat, F., Espagne, A., Dozova, N., Plaza, P., Yamamoto, J., Müller, P., Brettel, K., \& de la Lande, A. (2017). Ultrafast flavin photoreduction in an oxidized animal (6-4) photolyase through an unconventional tryptophan tetrad. Physical Chemistry Chemical Physics, 19(36), 24493-24504. https://doi. org/10.1039/c7cp04555g

40. Emmerich, H. J., Saft, M., Schneider, L., Kock, D., Batschauer, A., \& Essen, L. O. (2020). A topologically distinct class of photolyases specific for UV lesions within single-stranded DNA. Nucleic Acids Research, 48(22), 12845-12857. https://doi.org/10.1093/ nar/gkaa1147

41. Li, Y. F., Heelis, P. F., \& Sancar, A. (1991). Active site of DNA photolyase: Tryptophan-306 is the intrinsic hydrogen atom 
donor essential for flavin radical photoreduction and DNA repair in vitro. Biochemistry, 30(25), 6322-6329. https://doi. org/10.1021/bi00239a034

42. Byrdin, M., Villette, S., Eker, A. P. M., \& Brettel, K. (2007). Observation of an intermediate tryptophanyl radical in W306F mutant DNA photolyase from Escherichia coli supports electron hopping along the triple tryptophan chain. Biochemistry, 46(35), 10072-10077. https://doi.org/10.1021/bi700891f

43. Byrdin, M., Sartor, V., Eker, A. P. M., Vos, M. H., Aubert, C., Brettel, K., \& Mathis, P. (2004). Intraprotein electron transfer and proton dynamics during photoactivation of DNA photolyase from $E$. coli: review and new insights from an "inverse" deuterium isotope effect. Biochimica et Biophysica Acta - Bioenergetics, 1655(1-3), 64-70. https://doi.org/10.1016/j.bbabio.2003. 07.001 .

44. Yamamoto, J., Shimizu, K., Kanda, T., Hosokawa, Y., Iwai, S., Plaza, P., \& Muller, P. (2017). Loss of fourth electron-transferring tryptophan in animal (6-4) photolyase impairs DNA repair activity in bacterial cells. Biochemistry, 56(40), 5356-5364. https://doi.org/10.1021/acs.biochem.7b00366

45. Macheroux, P. (1999). UV-visible spectroscopy as a tool to study flavoproteins. In S. K. Chapman, \& G. A. Reid (Eds.), Flavoprotein Protocols (pp. 1-7, Methods in Molecular Biology, Vol. 131).

46. Brazard, J., Usman, A., Lacombat, F., Ley, C., Martin, M. M., Plaza, P., Mony, L., Heijde, M., Zabulon, G., \& Bowler, C. (2010). Spectro-temporal characterization of the photoactivation mechanism of two new oxidized cryptochrome/photolyase photoreceptors. Journal of the American Chemical Society, 132(13), 4935-4945. https://doi.org/10.1021/ja1002372

47. Yadav, D., Lacombat, F., Dozova, N., Rappaport, F., Plaza, P., \& Espagne, A. (2014). Real-time monitoring of chromophore isomerization and deprotonation during the photoactivation of the fluorescent protein Dronpa. The Journal of Physical Chemistry B, 119(6), 2404-2414. https://doi.org/10.1021/jp507094f

48. Yoshimura, A., Hoffman, M. Z., \& Sun, H. (1993). An evaluation of the excited-state absorption-spectrum of $\mathrm{Ru}(\mathrm{bpy})_{3}{ }^{2+}$ in aqueous and acetonitrile solutions. Journal of Photochemistry and Photobiology A: Chemistry, 70(1), 29-33. https://doi.org/10.1016/ 1010-6030(93)80005-t

49. Byrdin, M., Thiagarajan, V., Villette, S., Espagne, A., \& Brettel, K. (2009). Use of ruthenium dyes for subnanosecond detector fidelity testing in real time transient absorption. Review of Scientific Instruments, 80(4), 043102. https://doi.org/10.1063/1.31172 08

50. Ekvall, K., van der Meulen, P., Dhollande, C., Berg, L. E., Pommeret, S., Naskrecki, R., \& Mialocq, J. C. (2000). Cross phase modulation artifact in liquid phase transient absorption spectroscopy. Journal of Applied Physics, 87(5), 2340-2352. https://doi. org/10.1063/1.372185

51. Byrdin, M., Villette, S., Espagne, A., Eker, A. P. M., \& Brettel, K. (2008). Polarized transient absorption to resolve electron transfer between tryptophans in DNA photolyase. The Journal of Physical Chemistry B, 112(22), 6866-6871. https://doi.org/10.1021/jp711 $435 \mathrm{y}$

52. van Stokkum, I. H. M., Delmar, S. L., \& van Grondelle, R. (2004). Global and target analysis of time-resolved spectra. Biochimica et Biophysica Acta - Bioenergetics, 1657(2-3), 82-104. https://doi. org/10.1016/j.bbabio.2004.04.011

53. Henry, E. R., \& Hofrichter, J. (1992). Singular value decomposition - Application to analysis of experimental data. Methods in Enzymology, 210, 129-193. https://doi.org/10.1016/00766879(92)10010-B

54. Solar, S., Getoff, N., Surdhar, P. S., Armstrong, D. A., \& Singh, A. (1991). Oxidation of tryptophan and N-methylindole by $\mathrm{N}_{3}{ }^{\bullet}$, $\mathrm{Br}^{2 \bullet}-$, and $\left(\mathrm{SCN}_{)}{ }^{2 \bullet}-\right.$ radicals in light-water and heavy-water solutions: A pulse radiolysis study. The Journal of Physical Chemistry, 95(9), 3639-3643. https://doi.org/10.1021/j100162a038

55. Berndt, A., Kottke, T., Breitkreuz, H., Dvorsky, R., Hennig, S., Alexander, M., \& Wolf, E. (2007). A novel photoreaction mechanism for the circadian blue light photoreceptor Drosophila cryptochrome. Journal of Biological Chemistry, 282(17), 1301113021. https://doi.org/10.1074/jbc.M608872200

56. Liu, B., Liu, H., Zhong, D., \& Lin, C. (2010). Searching for a photocycle of the cryptochrome photoreceptors. Current Opinion in Plant Biology, 13(5), 578-586. https://doi.org/10.1016/j.pbi. 2010.09.005

57. Müller, P., Bouly, J.-P., Hitomi, K., Balland, V., Getzoff, E. D., Ritz, T., \& Brettel, K. (2014). ATP binding turns plant cryptochrome into an efficient natural photoswitch. Scientific Reports, 4, 5175. https://doi.org/10.1038/srep05175

58. Müller, P., \& Brettel, K. (2012). $\left[\mathrm{Ru}(\mathrm{bpy})_{3}\right]^{2+}$ as a reference in transient absorption spectroscopy: Differential absorption coefficients for formation of the long-lived 3MLCT excited state. Photochemical \& Photobiological Sciences, 11(4), 632-636. https:// doi.org/10.1039/c2pp05333k

59. Weigel, A., Dobryakov, A., Klaumünzer, B., Sajadi, M., Saalfrank, P., \& Ernsting, N. P. (2011). Femtosecond stimulated Raman spectroscopy of flavin after optical excitation. The Journal of Physical Chemistry B, 115(13), 3656-3680. https://doi.org/10.1021/jp111 7129

60. Massey, V., \& Palmer, G. (1966). On existence of spectrally distinct classes of flavoprotein semiquinones. A new method for quantitative production of flavoprotein semiquinones. Biochemistry, 5(10), 3181-3189. https://doi.org/10.1021/bi00874a016.

61. Gauden, M., Yeremenko, S., Laan, W., van Stokkum, I. H. M., Ihalainen, J. A., van Grondelle, R., Hellingwerf, K. J., \& Kennis, J. T. M. (2005). Photocycle of the flavin-binding photoreceptor AppA, a bacterial transcriptional antirepressor of photosynthesis genes. Biochemistry, 44(10), 3653-3662. https://doi.org/10.1021/ bi047359a

62. Marcus, R. A., \& Sutin, N. (1985). Electron transfers in chemistry and biology. Biochimica et Biophysica Acta, 811, 265-322. https://doi.org/10.1016/0304-4173(85)90014-X

63. Moser, C. C., \& Dutton, P. L. (1992). Engineering protein-structure for electron-transfer function in photosynthetic reaction centers. Biochimica et Biophysica Acta, 1101(2), 171-176. https://doi. org/10.1016/0005-2728(92)90205-g

64. Popović, D. M., Zmirić, A., Zarić, S. D., \& Knapp, E.-W. (2002). Energetics of Radical Transfer in DNA Photolyase. Journal of the American Chemical Society, 124(14), 3775-3782. https://doi.org/ $10.1021 / \mathrm{ja} 016249 \mathrm{~d}$

65. Lüdemann, G., Solov’yov, I. A., Kubař, T., \& Elstner, M. (2015). Solvent Driving Force Ensures Fast Formation of a Persistent and Well-Separated Radical Pair in Plant Cryptochrome. Journal of the American Chemical Society, 137(3), 1147-1156. https://doi. org/10.1021/ja510550g

66. Cailliez, F., Muller, P., Firmino, T., Pernot, P., \& de la Lande, A. (2016). Energetics of Photoinduced Charge Migration within the Tryptophan Tetrad of an Animal (6-4) Photolyase. Journal of the American Chemical Society, 138(6), 1904-1915. https://doi.org/ 10.1021/jacs.5b10938

67. Nunthaboot, N., Tanaka, F., Kokpol, S., Chosrowjan, H., Taniguchi, S., \& Mataga, N. (2009). Simulation of ultrafast non-exponential fluorescence decay induced by electron transfer in FMN binding protein. Journal of Photochemistry and Photobiology A: Chemistry, 201(2-3), 191-196. https://doi.org/10.1016/j.jphot ochem.2008.10.025

68. Tanaka, F., Lugsanangarm, K., Nunthaboot, N., Nueangaudom, A., Pianwanit, S., Kokpol, S., Taniguchi, S., \& Chosrowjan, H. (2015). Classification of the mechanisms of photoinduced electron transfer from aromatic amino acids to the excited flavins 
in flavoproteins. Physical Chemistry Chemical Physics, 17(26), 16813-16825. https://doi.org/10.1039/c5cp01432h

69. Lugsanangarm, K., Tamaoki, H., Nishina, Y., Kitamura, M., Nunthaboot, N., Tanaka, F., Taniguchi, S., \& Chosrowjan, H. (2020). Simultaneous analyses of the rates of photoinduced charge separation and recombination between the excited flavin and tryptophans in some flavoproteins: Molecular dynamics simulation. AIP Advances, 10(10), 14. https://doi.org/10.1063/5.0014718
70. Scheiner, S., \& Čuma, M. (1996). Relative stability of hydrogen and deuterium bonds. Journal of the American Chemical Society, 118(6), 1511-1521. https://doi.org/10.1021/ja9530376

71. Payne, G., Heelis, P. F., Rohrs, B. R., \& Sancar, A. (1987). The active form of Escherichia coli DNA photolyase contains a fully reduced flavin and not a flavin radical, both in vivo and in vitro. Biochemistry, 26(22), 7121-7127. https://doi.org/10.1021/bi003 $96 \mathrm{a} 038$

\section{Authors and Affiliations}

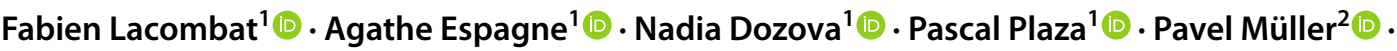 Hans-Joachim Emmerich ${ }^{3}$ (1) . Martin Saft ${ }^{3}$ (i) $\cdot$ Lars-Oliver Essen ${ }^{3}$ (i)}

\section{Pascal Plaza}

pascal.plaza@ens.psl.eu

$\triangle$ Pavel Müller

pavel.muller@i2bc.paris-saclay.fr

$\triangle$ Lars-Oliver Essen

essen@chemie.uni-marburg.de

Fabien Lacombat

fabien.lacombat@ens.psl.eu

Agathe Espagne

agathe.espagne@ens.psl.eu

Nadia Dozova

nadia.dozova@ens.psl.eu
Hans-Joachim Emmerich

emmeric7@staff.uni-marburg.de

Martin Saft

martin.saft@chemie.uni-marburg.de

1 PASTEUR, Département de Chimie, École Normale Supérieure, PSL University, CNRS, Sorbonne Université, 75005 Paris, France

2 Institute for Integrative Biology of the Cell (I2BC), Université Paris-Saclay, CEA, CNRS, 91198 Gif-sur-Yvette, France

3 Department of Chemistry, Center for Synthetic Microbiology, Philipps University, 35032 Marburg, Germany 